\title{
Evaluation of the Techniques Used In Analysis of Touch DNA Collected From Crime Tools in Hail, Kingdom Of Saudi Arabia
}

\author{
Nagy Alfadaly*1, Ahmed CH Kassab ${ }^{2}$ and Saad Faiz Al-Rasheedy ${ }^{2}$ \\ ${ }^{1}$ Department of Forensic Medicine, College of Medicine, Qassim University, Saudi Arabia \\ ${ }^{2}$ Department of Forensic Biology, College of Forensic Sciences, Naif University, Saudi Arabia
}

Submission: July 03, 2017; Published: July 20, 2017

*Corresponding author: Nagy Alfadaly, Department of Forensic Medicine, College of Medicine, Qassim University, Qassim, Saudi Arabia, Email: nmbayoumy@yahoo.co.uk

\begin{abstract}
Background: Touch DNA is a form of trace biological evidence which is the direct transfer of cellular material (e.g., shed skin cells) from an individual to an object or another individual during physical contact.

Aim of the work: to know the best and most reliable techniques used in the extraction and analysis of DNA to obtain DNA profiles from crime tools in Hail.

Methodology: The present study was done at Genetic Tests Division at criminal lab department; Department of criminal evidence; Hael District; Kingdom of Saudi Arabia. The work in the present study was divided into two phases: the first phase was a statistical evaluation for success of DNA extraction from different weapons and tools confiscated in crimes from Hail district for 5 years. During this period 229 crime tools were examined. The percentage of DNA extraction was $15.10 \%, 22.10 \%, 23.40 \%, 18.10 \%$ and $21.40 \%$ in these subsequent years, respectively. Knife was the tool that represented higher percent of DNA extraction (36.3\%). The second phase of the study was the practical part, in which we evaluated the results of touch DNA extraction from weapons used in criminal acts. Knife was the only weapon used in this part. Then we divided study groups into 4 as the following: Step 1 (Group A): in which 10 volunteers are involved to evaluate the effect of swap number on DNA quantity extracted from touched tools. Step 2 (Group B): in this group the 3 good shedders and 3 bad shedders from the previous group (A) were asked to repeat the experiment 3 times for each volunteer, aiming to evaluate three different extraction methods on DNA profiling from touched crime tools. Step 3 (Group C): in which the 3 good and 3 bad shedders (from group A) were asked to repeat the experiment (one Knife for each patient); and then sampling from the knife was collected by wet method, where the number of PCR runs was 29 in the first quantification trial; then 32 in the second trial and 35 in the third trial (C29, C23 and C35). This experiment aimed to evaluate the effect of number of PCR cycles on DNA profiling. Step 4 (Group D): the trial was repeated by the 3 good and 3 bad shedders; then knives were sampled by double method (two subsequent swabs). Then DNA was extracted by the best extraction method discovered from step 2 then, DNA was amplified by the best number of runs according to results obtained from step 3 of the present study. This is a collection for previous three groups.
\end{abstract}

Results: The double method of swabbing with Promiga kits for DNA extraction and PCR runs at 29 cycles for DNA amplification produced considerable DNA profiles from touch DNA.

Conclusion: Double sampling method (wet then dry) is the best to yield a large yield of touch DNA that can be sued for DNA profiling. Association of double swabbing method with Promiga kit for DNA extraction proved to be very efficient for DNA profiling of touch DNA collected from the studied cases.

Keywords: Touch DNA; DNA profiling; Double swab; PCR; Promiga kit

\section{Introduction}

Trace DNA analysis has become an integral part of forensic laboratory's workload and a key tool for investigators. Accordingly, there has been considerable research conducted in order to investigate the characteristics of trace DNA and the best method/s to improve its collection, amplification and interpretation [1]. Touch DNA is a form of trace biological evidence which is the direct transfer of cellular material (e.g., shed skin cells) from an individual to an object or to another individual during physical contact [2] The ability to obtain DNA profiles from a variety of touched objects (documents, bedding, shoes, firearms, drinking containers, pens, briefcase handles) has been reported in the literature [3-5]. 
A critical factor in the analysis of touch DNA evidence is the successful recovery of the trace biological material present. Touch DNA evidence is typically collected by swabbing the suspected area with a sterile cotton swab (referred to as "blindswabbing"). Using this approach, the nature of the collected biological material is not known and sampling of a generalized area is performed. The presence of surface grooves or crevices may impede the successful recovery of the often already small amount of biological material present. Additionally, a 'blindswabbing' approach will necessarily co-sample cellular material from the different individuals whose cells are present on the item, even if the individuals' cells are located in spatially distinct locations on the item. The recovery of admixed DNA profiles, which are often challenging to resolve particularly with low template DNA samples, is frequently observed [6,7]. If only a small amount of biological material was present from one of the donors, standard extraction and analysis techniques may fail to recover a profile from the minor contributor. Additionally, the type of swab or whether it was used dry or wet (pre-moistened with sterile water) may influence the amount of biological material that is collected due to differences in absorptivity and adsorptivity and the efficiency of release of the biological material [8]. Standard extraction methods may result in additional sample loss due to required physical manipulation of the sample or sample transfer steps [9].

\section{Aim of the study}

This study aimed to know the best and most reliable techniques used in the extraction and analysis of DNA to obtain DNA profiles from crime tools in Hail; identify the most important areas that are rich in touch DNA on the tools that are commonly used in committing crimes to guide specialists to focus on and avoid overlooking them; and attempt to improve the quality of the work in forensic laboratories.

\section{Methodology}

The present study was done at Genetic Tests Division at criminal lab department; Department of criminal evidence; Hael District; Kingdom of Saudi Arabia. The work in the present study was divided into two phases: the first phase was a statistical evaluation for success of DNA extraction from different weapons and tools in crimes from Hail district for 5 years. During this period 229 crime tools were examined. The percentage of DNA extraction was $15.10 \%, 22.10 \%, 23.40 \%, 18.10 \%$ and $21.40 \%$ in these years, respectively. Knife was the tool that represented higher percent of DNA extraction (36.3\%). The second phase of the study was the practical part, in which we evaluated the results of touch DNA extraction from weapons used in criminal acts. Knife was the only weapon used in this part.

Then we divided study groups into 4 as the following:

Step 1 (Group A): in which 10 volunteers put their hands for 5 minutes on water vapors to simulate the actual situations of sweating during criminal act. Then every volunteer clenched a knife (one knife to each volunteer) for 3-5 minutes, and then DNA was sampled from these knives by swap wetted by distilled water. DNA then was extracted by Promiga technique. Those volunteers were further subdivided into two categories according to quantity of extracted DNA; the first subgroup included good shedders and the second included the bad shedders. Then those volunteers were exposed to the same steps described previously except sampling method where we used Orlandi method [10] where sampling was done by double swab method (wet and dry swabs) [11] and these samples were marked as A-. This experiment aimed to evaluate the effect of swap number on DNA quantity extracted from touched tools.

Step 2 (Group B): in this group the 3 good shedders and 3 bad shedders (discovered from the previous group A) were asked to repeat the experiment 3 times for each volunteer. Thus, each volunteer had three samples, with a total of 18 samples. Then samples were exposed to extraction by three different extraction methods: the first six samples were extracted by Qiagen Kits and signed as (B-); the second 6 samples, DNA extraction was done by organic extraction using Phenol-Chlorofom and signed as (B--); then the last 6 samples were extracted by Promega Kits and signed as (B---). Then, DNA quantification was done using optical 96 well reaction plate (MicroAMPTM; Applied biosystem company) as described by manufacturer; using QuantifilerTM Human DNA Quantification kit. DNA quantity was measured by Sequence detection system 7000. DNA quantity was amplified by Amp FISTR $®$ Kit Amplification Identifiler $®$ PCR. This experiment aimed to evaluate and recognize the best extraction method on DNA profiling from touched crime tools.

Step 3 (Group C): in which the 3 good and 3 bad shedders were asked to repeat the experiment (one Knife for each patient); and then sampling was done by wet method. Then DNA was extracted by Promega Kits and DNA quantity was measured by Sequence detection system 7000. DNA quantity was amplified by Amp FISTR $®$ Kit Amplification Identifiler $®$ PCR; where the number of runs was 29 in first quantification trials; then 32 in the second trial and 35 in the third trial (C29, C23 and C35), respectively. This experiment aimed to recognize the effect of the number of runs (PCR cycles) on DNA profiling.

Step 4 (Group D): the trial was repeated by the 3 good and 3 bad shedders; knives then were sample by double method. Then DNA was extracted by the best method then, DNA was amplified by the best number of runs according to results of the previous trial of the present study. This is a collection for previous three groups.

\section{Results}

Quantification of DNA in step 1 (Group A): the DNA quantity in 10 volunteers and that of the best and least 3 shedders in studied cases with different sampling and extraction methods were present in (Tables 1-4). 


\section{Journal of Forensic Sciences \& Criminal Investigation}

Table 1: Shows DNA quantities (quantirfication) in studied volunteers with different sampling and extraction methods.

\begin{tabular}{|c|c|c|c|c|c|c|c|c|c|c|c|}
\hline \multirow{4}{*}{ Group A } & \multirow{2}{*}{ One wet sample } & $\mathrm{A} 1$ & A2 & A3 & A4 & A5 & A6 & A7 & A8 & A9 & $\mathrm{A} 10$ \\
\hline & & 0.287 & 0.226 & 0.225 & 0.0951 & 0.19 & 0.0769 & 0.259 & 0.0187 & 0.664 & 0.587 \\
\hline & \multirow{2}{*}{$\begin{array}{l}\text { Double samples } \\
\text { (wet and dry) }\end{array}$} & A-1 & A-2 & A-3 & A-4 & A-5 & A-6 & -- & -- & -- & -- \\
\hline & & 0.458 & 0.26 & 0.133 & 0.301 & 0.198 & 0.165 & -- & -- & -- & -- \\
\hline \multirow{6}{*}{ Group B } & \multirow{2}{*}{ Qiagen method } & B-1 & B-2 & B-3 & B-4 & B-5 & B-6 & -- & -- & -- & -- \\
\hline & & 0.007 & 0.753 & 0.0818 & 0.0718 & 0.0703 & 0.0633 & -- & -- & -- & -- \\
\hline & \multirow{2}{*}{$\begin{array}{l}\text { Organic } \\
\text { (Phenol- } \\
\text { chloroform) } \\
\text { method }\end{array}$} & B--1 & B--2 & B--3 & B--4 & B--5 & B--6 & -- & -- & -- & -- \\
\hline & & 0.564 & 0.31 & 0.265 & 0.0424 & 0.0638 & 0.132 & -- & -- & -- & -- \\
\hline & \multirow{2}{*}{$\begin{array}{l}\text { Promega } \\
\text { method }\end{array}$} & B---1 & B---2 & B---3 & B---4 & B---5 & B---6 & -- & -- & -- & -- \\
\hline & & 0.599 & 0.0523 & 0.023 & 0.0935 & 0.131 & 0.117 & -- & -- & -- & -- \\
\hline \multirow{2}{*}{ Group C } & \multirow{2}{*}{ At 29 runs } & $\mathrm{C} 1$ & $\mathrm{C} 2$ & C3 & $\mathrm{C} 4$ & $\mathrm{C} 5$ & C6 & -- & -- & -- & -- \\
\hline & & 0.335 & 0.0754 & 0.171 & 0.0871 & 0.227 & 0.0227 & -- & -- & -- & -- \\
\hline \multirow[b]{2}{*}{ Group D } & \multirow{2}{*}{$\begin{array}{c}\text { Double } \\
\text { sampling, } \\
\text { Promega at } 29 \\
\text { run }\end{array}$} & D1 & D2 & D3 & D4 & D5 & D6 & -- & -- & -- & -- \\
\hline & & 0.0854 & 0.314 & 0.0853 & 0.028 & 0.11 & 0.224 & -- & -- & -- & -- \\
\hline
\end{tabular}

The DNA profiling was carried out with all steps and resultant Alleles representing DNA profiles were presented in tables 2-4.

Table 2: Shows DNA profiling in third group where three Different Extraction Methods, Qiagen, Organic (phenol- chlorophorm), and Promega, were used.

\begin{tabular}{|c|c|c|c|c|c|c|c|c|c|c|c|c|c|c|c|c|c|}
\hline \multirow{2}{*}{$\begin{array}{l}\text { Extract. } \\
\text { Method }\end{array}$} & \multirow{2}{*}{ Sample } & D8S & D21 & D7S & CSF & D3S & \multirow{2}{*}{ THO1 } & D13 & D16 & D2S & D19 & Vw & $T$ & D18 & D5S & \multirow{2}{*}{ FGA } & \multirow{2}{*}{ Amel } \\
\hline & & 1179 & S11 & 820 & $1 \mathrm{PO}$ & 1358 & & S317 & S539 & 1338 & S433 & $\mathbf{A 1}$ & Pox & S51 & 816 & & \\
\hline Qiagen & 1-1 & ----- & ---- & ----- & ----- & ---- & ----- & ---- & ---- & ---- & ----- & ----- & ---- & $-\cdots--$ & ---- & ----- & --- \\
\hline Qiagen & B 1-2 & 9,12 & $\begin{array}{c}28 \\
31.2\end{array}$ & $\begin{array}{l}10 \\
10\end{array}$ & 13 & 16 & $\begin{array}{l}6 \\
6\end{array}$ & 12 & 13 & 19 & $\begin{array}{l}13 \\
14\end{array}$ & $\begin{array}{l}16 \\
18\end{array}$ & 8 & $\begin{array}{l}13 \\
14\end{array}$ & 13 & $\begin{array}{l}24 \\
29\end{array}$ & $X-Y$ \\
\hline Qiagen & B 1-3 & $\begin{array}{l}13, \\
15\end{array}$ & $\begin{array}{l}28 \\
29\end{array}$ & $\begin{array}{l}11, \\
11\end{array}$ & $\begin{array}{l}12 \\
12\end{array}$ & $\begin{array}{l}14, \\
15\end{array}$ & $\begin{array}{l}8, \\
8\end{array}$ & $\begin{array}{l}11, \\
12\end{array}$ & $\begin{array}{l}13 \\
13\end{array}$ & $\begin{array}{l}18 \\
18\end{array}$ & $\begin{array}{c}13, \\
15.2\end{array}$ & $\begin{array}{l}16, \\
17\end{array}$ & $\begin{array}{l}8, \\
11\end{array}$ & $\begin{array}{l}13 \\
20\end{array}$ & $\begin{array}{l}11 \\
12\end{array}$ & $\begin{array}{l}23 \\
25\end{array}$ & X-Y \\
\hline Qiagen & B 1-4 & ---- & ----- & ----- & ----- & ----- & ---- & ---- & ---- & ----- & ---- & ---- & ---- & ---- & ---- & ----- & ---- \\
\hline Qiagen & B 1-5 & ---- & $-\cdots-$ & ---- & $-\cdots--$ & ----- & ---- & ---- & ---- & ---- & ---- & ---- & ---- & ---- & ---- & ----- & ---- \\
\hline Qiagen & B 1-6 & $-\cdots--$ & ----- & ---- & ----- & ----- & $-\cdots--$ & ---- & ---- & ----- & ---- & ---- & ----- & ---- & ---- & ----- & ----- \\
\hline Organic & B 2-1 & ---- & ----- & ----- & ----- & ----- & ----- & ---- & ---- & ----- & ---- & ---- & ----- & ----- & ----- & ----- & ---- \\
\hline Organic & B 2-2 & 9,12 & $\begin{array}{c}28, \\
31.2\end{array}$ & $\begin{array}{l}10 \\
10\end{array}$ & $\begin{array}{l}12, \\
13\end{array}$ & $\begin{array}{l}15, \\
16\end{array}$ & $\begin{array}{l}6, \\
6\end{array}$ & $\begin{array}{l}12 \\
12\end{array}$ & $\begin{array}{l}11, \\
13\end{array}$ & $\begin{array}{l}16 \\
19\end{array}$ & $\begin{array}{l}13, \\
14\end{array}$ & $\begin{array}{l}16 \\
18\end{array}$ & $\begin{array}{l}8, \\
8\end{array}$ & $\begin{array}{l}13 \\
14\end{array}$ & $\begin{array}{l}10 \\
13\end{array}$ & $\begin{array}{l}24 \\
29\end{array}$ & $X-Y$ \\
\hline Organic & B 2-3 & $\begin{array}{l}13, \\
15\end{array}$ & $\begin{array}{l}28, \\
29\end{array}$ & $\begin{array}{l}11, \\
11\end{array}$ & $\begin{array}{l}12, \\
12\end{array}$ & $\begin{array}{l}14 \\
15\end{array}$ & $\begin{array}{l}8 \\
8\end{array}$ & $\begin{array}{l}11 \\
12\end{array}$ & $\begin{array}{l}13, \\
13\end{array}$ & $\begin{array}{l}18 \\
18\end{array}$ & $\begin{array}{c}13 \\
15.2\end{array}$ & $\begin{array}{l}16 \\
17\end{array}$ & $\begin{array}{l}8, \\
11\end{array}$ & $\begin{array}{l}13 \\
20\end{array}$ & $\begin{array}{l}11 \\
12\end{array}$ & $\begin{array}{l}23 \\
25\end{array}$ & X-Y \\
\hline Organic & B $2-4$ & ---- & ---- & ---- & ---- & ----- & ---- & ---- & ---- & ---- & ---- & ---- & ---- & ---- & ---- & ----- & ---- \\
\hline Organic & 2 & ---- & ---- & ---- & ---- & ---- & ---- & ---- & ---- & ---- & ---- & ---- & ---- & ---- & ---- & ---- & ---- \\
\hline Organic & В 2-6 & $\begin{array}{l}13, \\
14\end{array}$ & $\begin{array}{l}30, \\
32\end{array}$ & $\begin{array}{l}8, \\
10\end{array}$ & $\begin{array}{l}10 \\
10\end{array}$ & $\begin{array}{l}17, \\
17\end{array}$ & $\begin{array}{l}6 \\
6\end{array}$ & 8,11 & $\begin{array}{l}11, \\
12\end{array}$ & $\begin{array}{l}17 \\
17\end{array}$ & $\begin{array}{l}13 \\
13\end{array}$ & $\begin{array}{l}17 \\
18\end{array}$ & 8,8 & $\begin{array}{l}13 \\
16\end{array}$ & $\begin{array}{l}11 \\
12\end{array}$ & $\begin{array}{l}19 \\
24\end{array}$ & $X-Y$ \\
\hline Promega & B 3-1 & $\begin{array}{l}11, \\
11\end{array}$ & $\begin{array}{l}29 \\
30\end{array}$ & $\begin{array}{l}10, \\
10\end{array}$ & $\begin{array}{l}12 \\
12\end{array}$ & $\begin{array}{l}17 \\
17\end{array}$ & $\begin{array}{l}6, \\
6\end{array}$ & $\begin{array}{l}10, \\
11\end{array}$ & $\begin{array}{l}11, \\
11\end{array}$ & $\begin{array}{l}20, \\
23\end{array}$ & $\begin{array}{l}12, \\
15\end{array}$ & $\begin{array}{l}16 \\
17\end{array}$ & $\begin{array}{l}9, \\
9\end{array}$ & $\begin{array}{l}13 \\
13\end{array}$ & $\begin{array}{l}12 \\
12\end{array}$ & $\begin{array}{l}22 \\
24 \\
\end{array}$ & $X-Y$ \\
\hline Promega & В $3-2$ & 9,12 & $\begin{array}{c}28, \\
31.2\end{array}$ & $\begin{array}{l}10 \\
10\end{array}$ & $\begin{array}{l}12 \\
13\end{array}$ & $\begin{array}{l}15, \\
16\end{array}$ & $\begin{array}{l}6 \\
6\end{array}$ & $\begin{array}{l}12 \\
12\end{array}$ & $\begin{array}{l}11 \\
13\end{array}$ & $\begin{array}{l}16 \\
19\end{array}$ & $\begin{array}{l}13 \\
14\end{array}$ & $\begin{array}{l}16 \\
18\end{array}$ & $\begin{array}{l}8 \\
8\end{array}$ & $\begin{array}{l}13 \\
14\end{array}$ & $\begin{array}{l}10 \\
13\end{array}$ & $\begin{array}{l}24 \\
29\end{array}$ & $X-Y$ \\
\hline Promega & В $3-3$ & $\begin{array}{l}13 \\
15\end{array}$ & $\begin{array}{l}28 \\
29\end{array}$ & $\begin{array}{l}11, \\
11\end{array}$ & $\begin{array}{l}12 \\
12\end{array}$ & $\begin{array}{l}14 \\
15\end{array}$ & $\begin{array}{l}8, \\
8\end{array}$ & $\begin{array}{l}11 \\
12\end{array}$ & $\begin{array}{l}13 \\
13\end{array}$ & $\begin{array}{l}18 \\
18\end{array}$ & $\begin{array}{c}13 \\
15.2\end{array}$ & $\begin{array}{l}16 \\
17\end{array}$ & $\begin{array}{l}8, \\
11\end{array}$ & $\begin{array}{l}13 \\
20\end{array}$ & $\begin{array}{l}11 \\
12\end{array}$ & $\begin{array}{l}23 \\
25\end{array}$ & $X-Y$ \\
\hline
\end{tabular}




\begin{tabular}{|c|c|c|c|c|c|c|c|c|c|c|c|c|c|c|c|c|c|}
\hline Promega & В $3-4$ & $\begin{array}{l}11 \\
11\end{array}$ & $\begin{array}{c}29, \\
32.2\end{array}$ & $\begin{array}{l}10 \\
11\end{array}$ & $\begin{array}{l}10 \\
12\end{array}$ & $\begin{array}{l}15 \\
19\end{array}$ & $\begin{array}{c}7, \\
9.3\end{array}$ & $\begin{array}{l}12 \\
13\end{array}$ & $\begin{array}{l}11, \\
12\end{array}$ & $\begin{array}{l}17 \\
20\end{array}$ & $\begin{array}{c}15.2 \\
17\end{array}$ & $\begin{array}{l}15 \\
16\end{array}$ & 9,9 & $\begin{array}{l}14 \\
16\end{array}$ & 11,11 & $\begin{array}{l}20 \\
25\end{array}$ & $X-Y$ \\
\hline Promega & В $3-5$ & $\begin{array}{l}13 \\
13\end{array}$ & $\begin{array}{l}29 \\
30\end{array}$ & $\begin{array}{l}10 \\
10\end{array}$ & $\begin{array}{l}10 \\
11\end{array}$ & $\begin{array}{l}14 \\
16\end{array}$ & 6,9 & $\begin{array}{l}12 \\
12\end{array}$ & $\begin{array}{l}11, \\
11\end{array}$ & $\begin{array}{l}19 \\
20\end{array}$ & $\begin{array}{l}15 \\
16\end{array}$ & $\begin{array}{l}15 \\
16\end{array}$ & $\begin{array}{l}9, \\
11\end{array}$ & $\begin{array}{l}13 \\
15\end{array}$ & $\begin{array}{l}12 \\
13\end{array}$ & $\begin{array}{l}23 \\
24\end{array}$ & $X-Y$ \\
\hline Promega & В $3-6$ & $\begin{array}{l}13 \\
14\end{array}$ & $\begin{array}{l}30 \\
32\end{array}$ & $\begin{array}{l}8 \\
10\end{array}$ & $\begin{array}{l}10 \\
10\end{array}$ & $\begin{array}{l}17 \\
17\end{array}$ & 6,6 & 8,11 & $\begin{array}{l}11, \\
12\end{array}$ & $\begin{array}{l}17 \\
17\end{array}$ & $\begin{array}{l}13 \\
13\end{array}$ & $\begin{array}{l}17 \\
18\end{array}$ & 8,8 & $\begin{array}{l}13 \\
16\end{array}$ & $\begin{array}{l}11 \\
12\end{array}$ & $\begin{array}{l}19 \\
24\end{array}$ & $X-Y$ \\
\hline
\end{tabular}

Table 3: Shows DNA profiling in all volunteers (One wet sample, Promega at 29 run.

\begin{tabular}{|c|c|c|c|c|c|c|c|c|c|c|c|c|c|c|c|c|}
\hline Sample & $\begin{array}{c}\text { D8S } \\
1179\end{array}$ & $\begin{array}{l}\text { D21 } \\
\text { S11 }\end{array}$ & $\begin{array}{l}\text { D7S } \\
820\end{array}$ & $\begin{array}{l}\text { CSF } \\
1 P 0\end{array}$ & $\begin{array}{c}\text { D3S } \\
1358\end{array}$ & TH01 & $\begin{array}{c}\text { D13 } \\
\text { S317 }\end{array}$ & $\begin{array}{c}\text { D16 } \\
\text { S539 }\end{array}$ & $\begin{array}{c}\text { D2S } \\
1338\end{array}$ & $\begin{array}{l}\text { D19 } \\
\text { S433 }\end{array}$ & $\begin{array}{l}\text { VW } \\
\text { A1 }\end{array}$ & $\begin{array}{c}T \\
\text { Pox }\end{array}$ & $\begin{array}{l}\text { D18 } \\
\text { S51 }\end{array}$ & $\begin{array}{l}\text { D5S } \\
816\end{array}$ & FGA & Amel \\
\hline A1 & $\begin{array}{l}11, \\
11\end{array}$ & $\begin{array}{c}29 \\
32.2 \\
\end{array}$ & $\begin{array}{l}10 \\
11 \\
\end{array}$ & $\begin{array}{l}10 \\
12\end{array}$ & $\begin{array}{l}15 \\
19 \\
\end{array}$ & $7,9.3$ & $\begin{array}{l}12, \\
13\end{array}$ & $\begin{array}{l}11, \\
12\end{array}$ & ---- & $\begin{array}{c}15.2, \\
17\end{array}$ & $\begin{array}{l}16, \\
19 \\
\end{array}$ & $\begin{array}{l}9, \\
9\end{array}$ & ---- & $\begin{array}{l}11 \\
11\end{array}$ & $\begin{array}{l}25 \\
25 \\
\end{array}$ & X-Y \\
\hline A2 & $\begin{array}{l}11, \\
13\end{array}$ & $\begin{array}{l}29, \\
31\end{array}$ & $\begin{array}{c}9 \\
10\end{array}$ & $\begin{array}{l}12 \\
12\end{array}$ & $\begin{array}{l}15 \\
15\end{array}$ & 8,9 & $\begin{array}{l}12, \\
12\end{array}$ & $\begin{array}{l}9, \\
14\end{array}$ & 18,18 & $\begin{array}{l}14.2, \\
15.2\end{array}$ & $\begin{array}{l}17 \\
18\end{array}$ & $\begin{array}{l}8 \\
9\end{array}$ & 17,17 & $\begin{array}{l}12 \\
12\end{array}$ & $\begin{array}{l}21 \\
24\end{array}$ & $X-Y$ \\
\hline A3 & $\begin{array}{l}9 \\
12\end{array}$ & $\begin{array}{c}28 \\
31.2\end{array}$ & $\begin{array}{l}10 \\
10\end{array}$ & $\begin{array}{l}12 \\
13\end{array}$ & $\begin{array}{l}15 \\
16\end{array}$ & 6,6 & $\begin{array}{l}11, \\
12\end{array}$ & $\begin{array}{l}11 \\
13\end{array}$ & 16,19 & $\begin{array}{l}13 \\
14\end{array}$ & $\begin{array}{l}16 \\
18\end{array}$ & $\begin{array}{l}8 \\
8\end{array}$ & 13,14 & $\begin{array}{l}10 \\
13\end{array}$ & $\begin{array}{l}24 \\
29\end{array}$ & $X-Y$ \\
\hline A4 & $\begin{array}{l}13 \\
13\end{array}$ & $\begin{array}{l}29 \\
30\end{array}$ & $\begin{array}{l}10 \\
10\end{array}$ & ---- & $\begin{array}{l}14 \\
16\end{array}$ & 6,9 & $\begin{array}{l}12, \\
12\end{array}$ & $\begin{array}{l}11 \\
11\end{array}$ & ---- & $\begin{array}{l}15 \\
16\end{array}$ & $\begin{array}{l}15 \\
16\end{array}$ & $\begin{array}{c}9 \\
11\end{array}$ & 13,15 & $\begin{array}{l}12 \\
13\end{array}$ & $\begin{array}{l}23 \\
24\end{array}$ & X-Y \\
\hline A5 & $\begin{array}{l}11 \\
15\end{array}$ & $\begin{array}{l}28 \\
31.2\end{array}$ & $\begin{array}{l}8, \\
8\end{array}$ & 11,12 & $\begin{array}{l}15 \\
16\end{array}$ & 6,7 & $\begin{array}{l}8, \\
13\end{array}$ & $\begin{array}{l}12 \\
13\end{array}$ & $\begin{array}{l}17 \\
18\end{array}$ & $\begin{array}{l}13.2 \\
14.2\end{array}$ & $\begin{array}{l}17 \\
18\end{array}$ & $\begin{array}{c}8 \\
10\end{array}$ & 12,15 & $\begin{array}{l}10 \\
11\end{array}$ & $\begin{array}{l}21 \\
22\end{array}$ & $X-Y$ \\
\hline A6 & $\begin{array}{l}14 \\
14\end{array}$ & --- & $\begin{array}{l}8, \\
8\end{array}$ & --- & $\begin{array}{l}17 \\
17\end{array}$ & 6,6 & $\begin{array}{l}8, \\
11\end{array}$ & --- & $\begin{array}{l}17 \\
17\end{array}$ & $\begin{array}{l}13 \\
13\end{array}$ & --- & $\begin{array}{l}8 \\
8\end{array}$ & ---- & $\begin{array}{l}11 \\
12\end{array}$ & ---- & $\mathrm{X}-?$ \\
\hline A7 & $\begin{array}{l}11, \\
11\end{array}$ & 29,30 & $\begin{array}{l}10 \\
10\end{array}$ & 12,12 & $\begin{array}{l}17 \\
17\end{array}$ & 6,6 & $\begin{array}{l}10 \\
11\end{array}$ & 11,11 & 20,23 & $\begin{array}{l}12 \\
15\end{array}$ & $\begin{array}{l}16 \\
17\end{array}$ & $\begin{array}{l}9 \\
9\end{array}$ & 13,13 & $\begin{array}{l}12 \\
12\end{array}$ & ---- & X-Y \\
\hline A8 & $\begin{array}{l}12 \\
12\end{array}$ & $\begin{array}{c}31 \\
31.2\end{array}$ & $\begin{array}{c}9 \\
13\end{array}$ & 8,11 & $\begin{array}{l}14 \\
17\end{array}$ & 6,7 & $\begin{array}{l}12, \\
13\end{array}$ & 10,11 & 20,24 & $\begin{array}{c}14 \\
15.2\end{array}$ & $\begin{array}{l}17 \\
18\end{array}$ & $\begin{array}{l}8, \\
9\end{array}$ & 13,14 & $\begin{array}{l}12 \\
12\end{array}$ & $\begin{array}{l}21 \\
21\end{array}$ & X-Y \\
\hline A9 & $\begin{array}{l}13 \\
15\end{array}$ & 28,29 & $\begin{array}{l}11 \\
11\end{array}$ & 12,12 & $\begin{array}{l}14 \\
15\end{array}$ & 8,8 & $\begin{array}{l}11, \\
12\end{array}$ & 13,13 & 18,18 & $\begin{array}{c}13 \\
15.2\end{array}$ & $\begin{array}{l}16 \\
17\end{array}$ & $\begin{array}{l}8 \\
11\end{array}$ & 13,13 & $\begin{array}{l}11 \\
12\end{array}$ & $\begin{array}{l}23 \\
25\end{array}$ & X-Y \\
\hline A10 & $\begin{array}{l}13 \\
13\end{array}$ & $\begin{array}{l}32.2 \\
32.2\end{array}$ & $\begin{array}{l}10 \\
10\end{array}$ & 10,11 & $\begin{array}{l}16 \\
17\end{array}$ & 7,9 & $\begin{array}{l}11, \\
11\end{array}$ & 10,11 & 17,18 & $\begin{array}{l}13 \\
16\end{array}$ & $\begin{array}{l}16 \\
17\end{array}$ & $\begin{array}{l}8 \\
8\end{array}$ & 12,14 & $\begin{array}{l}11 \\
12\end{array}$ & $\begin{array}{l}24 \\
25\end{array}$ & $X-Y$ \\
\hline
\end{tabular}

Table 4: Shows the DNA profiles resulting from the combined use of double sampling, Promega extraction method and PCR run at 29 cycles.

\begin{tabular}{|c|c|c|c|c|c|c|c|c|c|c|c|c|c|c|c|c|}
\hline Sample & $\begin{array}{c}\text { D8S } \\
1179\end{array}$ & $\begin{array}{l}\text { D21 } \\
\text { S11 }\end{array}$ & $\begin{array}{l}\text { D7S } \\
820\end{array}$ & $\begin{array}{l}\text { CSF } \\
\text { 1PO }\end{array}$ & $\begin{array}{c}\text { D3S } \\
1358\end{array}$ & THO1 & $\begin{array}{c}\text { D13 } \\
\text { S317 }\end{array}$ & $\begin{array}{c}\text { D16 } \\
\text { S539 }\end{array}$ & $\begin{array}{c}\text { D2S } \\
1338\end{array}$ & $\begin{array}{c}\text { D19 } \\
\text { S433 }\end{array}$ & $\begin{array}{l}\text { VW } \\
\text { A1 }\end{array}$ & $\begin{array}{c}T \\
\text { Pox }\end{array}$ & $\begin{array}{l}\text { D18 } \\
\text { S51 }\end{array}$ & $\begin{array}{l}\text { D5S } \\
816\end{array}$ & FGA & Amel \\
\hline D1 & $\begin{array}{l}11 \\
11\end{array}$ & $\begin{array}{l}29 \\
30\end{array}$ & $\begin{array}{l}10 \\
10\end{array}$ & $\begin{array}{l}12 \\
12\end{array}$ & $\begin{array}{l}17 \\
17\end{array}$ & 6,6 & $\begin{array}{l}10 \\
11\end{array}$ & $\begin{array}{l}11 \\
11\end{array}$ & $\begin{array}{l}20 \\
23\end{array}$ & $\begin{array}{l}12 \\
15\end{array}$ & $\begin{array}{l}16 \\
17\end{array}$ & $\begin{array}{l}9 \\
9\end{array}$ & $\begin{array}{l}13 \\
13\end{array}$ & $\begin{array}{l}12 \\
12\end{array}$ & $\begin{array}{l}22 \\
24\end{array}$ & X-Y \\
\hline D2 & $\begin{array}{l}9 \\
12\end{array}$ & $\begin{array}{c}28 \\
31.2\end{array}$ & $\begin{array}{l}10 \\
10\end{array}$ & $\begin{array}{l}12 \\
13\end{array}$ & $\begin{array}{l}15 \\
16\end{array}$ & 6,6 & $\begin{array}{l}12 \\
12\end{array}$ & $\begin{array}{l}11 \\
13\end{array}$ & $\begin{array}{l}16 \\
19\end{array}$ & $\begin{array}{l}13 \\
14\end{array}$ & $\begin{array}{l}16 \\
18\end{array}$ & $\begin{array}{l}8 \\
8\end{array}$ & $\begin{array}{l}13 \\
14\end{array}$ & $\begin{array}{l}10 \\
13\end{array}$ & $\begin{array}{l}24 \\
29\end{array}$ & $X-Y$ \\
\hline D3 & $\begin{array}{l}13 \\
15\end{array}$ & $\begin{array}{l}28 \\
29\end{array}$ & $\begin{array}{l}11 \\
11\end{array}$ & $\begin{array}{l}12 \\
12\end{array}$ & $\begin{array}{l}14, \\
15\end{array}$ & 8,8 & $\begin{array}{l}11 \\
12\end{array}$ & $\begin{array}{l}13 \\
13\end{array}$ & $\begin{array}{l}18 \\
18\end{array}$ & $\begin{array}{c}13 \\
15.2\end{array}$ & $\begin{array}{l}16 \\
17\end{array}$ & $\begin{array}{c}8 \\
11\end{array}$ & $\begin{array}{l}13 \\
20\end{array}$ & $\begin{array}{l}11 \\
12\end{array}$ & $\begin{array}{l}23 \\
25\end{array}$ & X-Y \\
\hline $\mathrm{D} 4$ & $\begin{array}{l}11 \\
11\end{array}$ & $\begin{array}{c}29 \\
32.2\end{array}$ & $\begin{array}{l}10 \\
11\end{array}$ & $\begin{array}{l}10 \\
12\end{array}$ & $\begin{array}{l}15 \\
19\end{array}$ & $6,9.3$ & $\begin{array}{l}12 \\
13\end{array}$ & $\begin{array}{l}11 \\
12\end{array}$ & $\begin{array}{l}17 \\
20\end{array}$ & $\begin{array}{c}15.2 \\
17\end{array}$ & $\begin{array}{l}15 \\
16\end{array}$ & $\begin{array}{l}9 \\
9\end{array}$ & $\begin{array}{l}14 \\
14\end{array}$ & $\begin{array}{l}11 \\
11\end{array}$ & $\begin{array}{l}20 \\
25\end{array}$ & X-Y \\
\hline D5 & $\begin{array}{l}13 \\
13\end{array}$ & $\begin{array}{l}29 \\
30\end{array}$ & $\begin{array}{l}10 \\
11\end{array}$ & $\begin{array}{l}10 \\
11\end{array}$ & $\begin{array}{l}14 \\
16\end{array}$ & 6,9 & $\begin{array}{l}12 \\
12\end{array}$ & $\begin{array}{l}11 \\
11\end{array}$ & $\begin{array}{l}19 \\
20\end{array}$ & $\begin{array}{l}15 \\
16\end{array}$ & $\begin{array}{l}15 \\
16\end{array}$ & $\begin{array}{c}9 \\
11\end{array}$ & $\begin{array}{l}13 \\
15\end{array}$ & $\begin{array}{l}12 \\
13\end{array}$ & $\begin{array}{l}23 \\
24\end{array}$ & X-Y \\
\hline D6 & $\begin{array}{l}13 \\
14\end{array}$ & $\begin{array}{c}30 \\
32.2\end{array}$ & $\begin{array}{l}10 \\
10\end{array}$ & $\begin{array}{l}10 \\
10\end{array}$ & $\begin{array}{l}17 \\
17\end{array}$ & 6,6 & $\begin{array}{l}8, \\
11\end{array}$ & $\begin{array}{l}11 \\
11\end{array}$ & $\begin{array}{l}17 \\
17\end{array}$ & $\begin{array}{l}13 \\
13\end{array}$ & $\begin{array}{l}17 \\
18\end{array}$ & $\begin{array}{l}8 \\
8\end{array}$ & $\begin{array}{l}13 \\
16\end{array}$ & $\begin{array}{l}11 \\
11\end{array}$ & $\begin{array}{l}19 \\
24\end{array}$ & $X-Y$ \\
\hline
\end{tabular}

\section{Discussion}

Touch DNA is one of the important sources of DNA used by criminal laboratory specialists to detect suspected criminal. This DNA transmitted from person to instrument when the criminal touches or clenches the instrument. The rate of skin cells lost on the daily basis was estimated at about 400000 cells/day [7]. Unfortunately, these cells cannot be used easily in DNA analysis, due to several reasons. These cells are keratinized dead cells, most of them lost their nuclei, which are the source of DNA, and even these nuclei- if exist- they contain destroyed DNA [12]. In addition, the transfer of touch DNA did not depend on the time of touch process itself, but it depends on the number of touches and presence of pressure or friction between skin and touched instrument help in transfer of more cells. The process of DNA profiling depends on the identification of sites that contain touched DNA, kits used for identification and the method of sampling [7]. 
Other problem that faces who works to get touch DNA profiling include the minute amount of identified DNA, so the samples in many cases cannot produce complete DNA profiles. In addition, the sample itself may be combined with other samples present in the scene of the crime that result in mixed profiles that make the process interpretation of profiles and the individuals very difficult [13]. Touch DNA analysis that cannot be analyzed by routine techniques require newer technologies (methods and appliances) for its quantification and identification. These technologies include for example newer commercial multiplexes, with increased efficiency of buffer systems and increase in sensitivity of detection methods [14]. In addition, the technique of purification is an important step that governs the results of getting DNA profiles from touch DNA. This method depends on removal of salts, ions and nucleotides, which are not used in PCR. This can be achieved by filtration of extracted touch DNA with special devices such as Microcon and Qiagen MinElute columns [15].

In cases, where such devices or advanced techniques were not available, it is possible to adopt other strategies to increase the amount of DNA extracted from touch samples, e.g., increase the number of runs and use of double sampling method [16]. In the present study we aimed at studying three possible methods used to increase the sensitivity of touch DNA in DNA profiling in criminal cases. Results of the present study as shown in Tables 1-4 revealed that, the double method of swabbing and Promiga kits for DNA extraction associated with PCR runs at 29 have been the best methods for DNA profiling from touch DNA.

Double swab technique was originally advocated by [8] for recovery of saliva from skin. A wet cotton swab and a second dry cotton swab are applied onto the same surface of interest in the double swab technique. The use of the double swab technique improved the recovery of saliva compared to the use of the classical stain recovery technique. Furthermore, the double swab technique was also used to retrieve trace level of DNA in the study of the primary and secondary DNA transfer $[5,17,18]$.

Going with results of the present study, [11] concluded that, the use of a wet and dry double swab technique for recovery of touched evidence improves the DNA profiling results and is useful in collecting the evidence at the crime scenes.

This study shows that

a) The single wet swab may not recover epithelial cells present on the surface efficiently.

b) DNA recovered by the second swabs alone can produce DNA profiles.

Since detectable amount of DNA could be recovered by the second dry swab from the moisture left by the first wet swab, the DNA profiling results can be improved by pooling the first wet and the second dry swabs together for extraction. When the trace amounts of DNA obtained from a tested sample are close to the limits of sensitivity of the DNA profiling methods, obtaining a useful profile will depend on how well the sample is taken.

Regarding the number of runs, in the late 1990s, the United Kingdom's Forensic Science Service pioneered the appliาcation of LCN analysis through increasing the number of PCR cycles in order to improve DNA detection sensitivity [19]. Instead of using their STR kit manufacturer's recommended 28 cycles, which has a theoretical yield of 67 million cop 7 ies for each target DNA sequence, an additional six cycles (34 total) are run to provide a theoretical yield of 4.3 billion copies or a 64 -fold improvement in sensitivity. A more recent approach to highsensitivity DNA testing uses a three-cycle signal enhance $\neg$ ment to provide a theoretical 16 -fold improvement in sensitivity [20]. This increase in PCR amplification cycles enables STR typing to routinely obtain results with samples containing less than $100 \mathrm{pg}$ of DNA template. However, applicaᄀtion of low level DNA results should be approached with caution due to the possibilities of allele drop-out, allele drop-in, and increased risks of collectionbased and laboratory-based contamination. In Budowle B (2001) [21] from the FBI Laboratory proposed several alterna 7 tive strategies to boost STR profile signals without increasing PCR cycle number and experiาencing the concomitant increased risk of contamination. These strategies include: (1) increasing the injection time on the capillary electrophoresis (CE) instrument, (2) sample salt reduction through filtration of the PCR product to remove ions that compete with the STR amplicons when being injected into the capillary or use of form amide with lower conductivity, and (3) reducing the PCR volume to get a more concentrated PCR product [21-24].

\section{Conclusion}

In short, double sampling method (wet then dry) is the best to give a large yield of touch DNA. In addition, the run at 29 with Promiga kit were the valuable tools for DNA profiling of touch DNA from studied cases.

\section{References}

1. Van Oorschot Ra, Ballantyne Kn, Mitchell Rj (2010) Forensic trace DNA: a review. Investigative Genetics 1: 14.

2. Hanson EK, Ballantyne J (2013) Getting blood from a stone: ultrasensitive forensic DNA profiling of microscopic bio-particles recovered from 'touch DNA' evidence. Methods Mol Biol 1039: 3-17.

3. Balogh MK, Burger J, Bender K, Alt KW (2003) STR genotyping and mtDNA sequencing of latent fingerprint on paper. Forensic Sci Int 137(2-3): 188-195.

4. Barbaro A, Cormaci P, La MA (2004) Anonymous letters? DNA and fingerprints technologies combined to solve a case. Forensic Sci Int 146: S133-S134.

5. Bright JA, Petricevic SF (2004) Recovery of trace DNA and its application to DNA profiling of shoe insoles. Forensic Sci Int 145(1): 7-12.

6. Raymond JJ, van Oorschot RA, Gunn PR, Walsh SJ, Roux C (2009) Trace evidence characteristics of DNA: A preliminary investigation of the persistence of DNA at crime scenes. Forensic Sci Int Genet 4 (1): 26-33. 
7. Wickenheiser RA (2002) Trace DNA: a review, discussion of theory, and application of the transfer of trace quantities of DNA through skin contact. J Forensic Sci 47(3): 442-450.

8. Sweet D, Lorente M, Lorente JA (1997) An improved method to recover saliva from human skin: the double swab technique. J Forensic Sci 42(2): 320-322

9. Farash K, Hanson EK, Ballantyne J (2015) Enhanced Genetic Analysis of Single Human Bioparticles Recovered by Simplified Micromanipulation from Forensic 'Touch DNA' Evidence. J Vis Exp 97: e52612.

10. Orlando A (2012) The recovery and analysis of DNA from fired cartridge casings. Phd thesis in forensic science P. 1-9.

11. Pang PCM, Cheung BKK (2007) Double swab technique for collecting touched evidence; a brief communication. Legal Medicine 9(4): 181184.

12. Kita T (2008) Morphological study of fragmented DNA on touched objects. Forensic Sci Int Genet 3(1): 32-36.

13. Butler JM (2012) Advanced Topics in Forensic DNA Typing: Methodology. Walham: Academic Press. Chapter 1, p. 1-27.

14. Hedman J, Nordgaard A, Rasmusson B, Ansell R, Rådström P (2009) Improved forensic DNA analysis through the use of alternative DNA polymerases and statistical modeling of DNA profiling. Biotechniques 47(5): 951-958.

15. Smith PJ, Ballantyne J (2007) Simplified low-copy-number DNA analysis by post-PCR purification. J Forensic Sci 52(4): 820-829.

16. Karla GB, Saskia MV, Martine V, Titia S (2012) Comparison of stubbing and the double swab method for collecting offender epithelial material from a victim's skin. Forensic Science International: Genetics 6(2): 219-223.

17. Esslinger KJ, Siegel JA, Spillane H, Stallworth S (2004) Using STR analysis to detect human DNA from exploded pipe bomb devices. J Forensic Sci 49(3):481-484

18. Poy AL, van Oorschot RAH (2006) Trace DNA presence, origin, and transfer within a forensic biology laboratory and its potential effect on casework. J Forensic Identification 56(4): 558-576.

19. Gill P (2000) An investigation of the rigor of interpretation rules for STRs derived from less than $100 \mathrm{pg}$ of DNA. Forensic Science International 112(1): 17-40.

20. Caragine $\mathrm{T}$ (2009) Validation of testing and interpretation protocols for low template DNA samples using AmpFISTR Identifiler. Croatian Medical Journal 50(3): 250-267.

21. Budowle B (2001) Low copy number - consideration and caution. Proceedings of the twelfth international symposium on human identification. Madison, WI: Promega Corporation.

22. Whitaker JP (2001) A comparison of the characteristics of profiles produced with the AMPFISTR SGM Plus multiplex system for both standard and low copy number (LCN) STR DNA analysis. Forensic Science International 123(2-3): 215-223.

23. Saravo L, Spitaleri S, Piscitello D, Travali S (2004) DNA typing from steel cable. International Congress Serirs 1261: 473-475.

24. Patrick D, René M, Sofia Z, Thirsa K, Jeroen P, et al. (2011) A sensitive method to extract DNA from biological traces present on ammunition for the purpose of genetic profiling. Int J Legal Med 125(4): 597-602.

\section{Your next submission with Juniper Publishers will reach you the below assets}

- Quality Editorial service

- Swift Peer Review

- Reprints availability

- E-prints Service

- Manuscript Podcast for convenient understanding

- Global attainment for your research

- Manuscript accessibility in different formats

( Pdf, E-pub, Full Text, Audio)

- Unceasing customer service

Track the below URL for one-step submission https://juniperpublishers.com/online-submission. 